\title{
Cytological Grading of Chronic Lymphocytic Thyroiditis and Correlation with Thyroid Profile
}

\author{
Netra M Sajjan', B R Vani ${ }^{1 *}$, Srinivasamurthy $V^{1}$, V Vijayakumari² \\ Dept of ${ }^{1}$ Pathology and ${ }^{2}$ Biochemistry, ESICMC \& PGIMSR, Bangalore
}

\begin{abstract}
Background: Chronic lymphocytic thyroiditis is a thyroid specific autoimmune disease often seen in middle aged women, although rarely do occur in men, children. This disease is characterized by antibody directed against thyroid peroxidase, called antimicrosomal antibody. The present study was undertaken to evaluate the various cytological features occurring in HT and to correlate with clinical and serological findings.

Method: The study was conducted in department of Pathology from May 2017 to August 2017. The cases diagnosed as HT by FNAC were taken up for the study. Cytomorphologic features were reviewed microscopically and graded as per Bhatia et al.

Results: Fifty cases were diagnosed as lymphocytic thyroiditis. Age of the patient ranged from 7-56 years. Clinically 41 of 50 cases (82\%) presented with diffuse thyroid enlargement. In our study we had 31 cases (62\%) of grade 2 thyroiditis, 15 and 4 cases each of grade 1 and grade 3 respectively. We observed increased TSH values in 100\% of G3 thyroiditis and 64.5\% of G2 thyroiditis. None of the Grade 1 thyroiditis had increased TSH levels. The statistical correlation between grades of thyroiditis with T3, T4 and TSH levels was found to be significant with $\mathrm{p}$ values $<0.05$.

Conclusion: FNAC is simple cost effective and quick method for diagnosing HT. Also combined evaluation of HT with clinical findings and thyroid profile promotes more accurate diagnosis and early institution of therapy and follow up. FNAC is also necessary to rule out malignant lesions like lymphoma and papillary carcinoma at preliminary cytological level.
\end{abstract}

Keywords: Thyroiditis, Grade, Cytology, Fine needle aspirate, Lymphocytes

\section{Introduction}

Chronic lymphocytic thyroiditis being synonymous with Hashimoto's thyroiditis(HT), is a thyroid specific autoimmune disease often seen in middle aged women, although rarely do occur in men, children ${ }^{1}$. Clinically HT presents as minimal to moderate diffuse enlargement of thyroid gland. HT is considered the most common cause of hypothyroidism, although in the initial phase mild Hashitoxicosis is known ${ }^{2}$. This disease is characterised by antibody directed against thyroid peroxidise, called antimicrosomal antibody ${ }^{3}$, and often seen in high titres. Other antibodies are specific for thyroglobulin, colloid antigens and for thyroid-stimulating hormone (TSH) receptor. Classical destruction of thyroid by lymphocytic infiltrate is a feature in HT and hence also called as stroma lymphomatosum. In cytology, HT falls under diagnostic category II (Benign) in The 2017 Bethesda system for reporting thyroid cytopathology. FNA enables primary diagnosis of HT in most cases and also early diagnosis in some cases where serological changes are not yet $\operatorname{seen}^{2}$. The present study was undertaken to evaluate the various cytological features occurring in HT and to correlate with clinical and serological findings.

\section{Materials and Methods}

The study was conducted in the department of Pathology from May 2017 to August 2017. The cases diagnosed as HT by FNAC were taken up for the study. Clinical details were obtained from the patient case files. FNAC was performed by both aspiration and non aspiration techniques using a 24-gauge needle. Slides stained by Leishman and H\&E stains were evaluated. Cytomorphologic features were reviewed microscopically and graded into 3 grades as per Bhatia et $\mathrm{al}^{5}$. Grade 1 thyroiditis shows few lymphoid cells infiltrating the follicles. Mild to moderate lymphocytic infiltrate with Hurthle cell change is seen in grade 2 thyroiditis. Grade 3 thyroiditis shows florid lymphocytic infiltrate with germinal center formation and scant follicular cells. Thyroid function tests were advised routinely for all patients prior to FNAC and values of T3, T4, TSH recorded were noted. Cytological grades of thyroiditis were further correlated with the clinical findings and thyroid hormone assay.

\section{Result}

Fifty cases were diagnosed as lymphocytic thyroiditis. Age of the patient ranged from 7-56 years with a mean age of 36.3 years. Majority of the patients $(32 \%)$ were in the age group of 40-49 years. Only one patient belonged to age group of less than 10 yrs. Similar to literature studies, we also observed female preponderance with female to male ratio being $24: 1^{4,5,6,7}$. Clinically 41 of 50 cases 
(82\%) presented with diffuse thyroid enlargement while 9 (18\%) cases exhibited nodular enlargement of thyroid. One patient of grade 1 thyroiditis had increased BMR and weight loss. 24 out of 50 patients clinically presented with cold intolerance.

On cytology, most of the smears belonged to Grade 2 thyroiditis and showed chiefly hurthle cells in small clusters, singly and scattered along with polymorphic population of lymphoid cells, epitheloid cells and giant cells (Fig 3\&4).

Smears with few lymphocytic infiltrating the thyroid follicles and with occasional Ashkenazy cells, in hemorrhagic background were of grade 1 HT (Fig 1).

Smears categorized as grade 3 exhibited florid lymphocytic infiltrate with few follicular cells (Fig 5\&6). In our study we had 31 cases $(62 \%)$ of grade 2 thyroiditis, 15 and 4 cases each of grade 1 and grade 3 respectively (Table 1 ).

TSH values were obtained in all cases. We observed increased TSH values in $100 \%$ of G3 thyroiditis and $64.5 \%$ of G 2 thyroiditis. None of the Grade 1 thyroiditis had increased TSH levels. The statistical correlation between grades of thyroiditis with T3, T4 and TSH levels was found to be significant with $p$ values $<0.05$. Chi square tests values were also obtained (Table 4).

\section{Discussion}

Hashimotos thyroiditis was first described by Hakaru Hashimoto in $1912^{8}$. HT is caused by breakdown of selftolerance to thyroid autoantigens, causing activation of CD4 T helper cells. Recruited autoreactive B cells secretes a variety of circulating antibodies like antithyroglobulin and antithyroid peroxidase antibodies ${ }^{6}$, which causes progressive depletion of thyrocytes with infiltration by mononuclear cell infiltration replacing them and eventually causing organ destruction and fibrosis. Diagnosis of these lesions are necessary as patient subsequently becomes hypothyroid with need for lifelong thyroid supplementation. Long term follow up needed, in view of reported cases of risk of transformation to extranodal B cell lymphoma and thyroid carcinoma. HT is more prevalent between the age groups of 45 to 65 years and common in women than in men with female to male ratio of $10: 1$ to $20: 1 .^{6}$ In our study majority of the patients were seen in the $3^{\text {rd }}$ and $4^{\text {th }}$ decade which was comparable to studies conducted

Table 1: Grading of lymphocytic thyroiditis on cytology ${ }^{\text {Bhatia }}$

\begin{tabular}{|l|l|l|}
\hline Grades & Morphology & $\%$ in our study \\
\hline Grade 1 & $\begin{array}{l}\text { Few lymphoid cells infiltrating the follicles/ increased number of } \\
\text { lymphocytes in the background }\end{array}$ & $30 \%(15$ cases) \\
\hline Grade 2 & $\begin{array}{l}\text { Moderate lymphocytic infiltration or mild lymphocytic infiltration with } \\
\text { Hurthle cell change/giant cells/anisonucleosis }\end{array}$ & $62 \%(31$ cases) \\
\hline Grade 3 & $\begin{array}{l}\text { Florid lymphocytic inflammation with germinal center formation, very } \\
\text { few follicular cells left. }\end{array}$ & $08 \%$ (04 cases) \\
\hline
\end{tabular}

Table 2: Comparison between the present study and with various other studies (Comparison with 2 more studies done ')

\begin{tabular}{|c|c|c|c|c|c|c|c|c|}
\hline & No. of & Age & \multicolumn{2}{|c|}{ Sex } & \multicolumn{2}{|c|}{ Clinical presentation } & \multicolumn{2}{|c|}{ Cytological grading } \\
\hline & & & M & $\mathbf{F}$ & Nature & Percentage & Grades & Percentage \\
\hline \multirow[t]{3}{*}{ Bhatia et al. } & \multirow[t]{3}{*}{76} & \multirow[t]{3}{*}{$6-60$} & \multirow[t]{3}{*}{06} & \multirow[t]{3}{*}{70} & Diffuse & 89.47 & G1 & 38.67 \\
\hline & & & & & \multirow[t]{2}{*}{ Nodular } & \multirow[t]{2}{*}{2.63} & $\mathrm{G} 2$ & 44 \\
\hline & & & & & & & G3 & 17.33 \\
\hline \multirow[t]{3}{*}{ Jayarma et al } & \multirow[t]{3}{*}{40} & \multirow[t]{3}{*}{$40-50$} & \multirow[t]{3}{*}{0} & \multirow[t]{3}{*}{40} & Diffuse & -- & G1 & 13.5 \\
\hline & & & & & \multirow[t]{2}{*}{ Nodular } & \multirow[t]{2}{*}{-} & G2 & 62.16 \\
\hline & & & & & & & G3 & 24.32 \\
\hline \multirow[t]{3}{*}{ Friedman et al } & \multirow[t]{3}{*}{40} & \multirow[t]{3}{*}{$18-71$} & \multirow[t]{3}{*}{7} & \multirow[t]{3}{*}{33} & Diffuse & 81.8 & G1 & - \\
\hline & & & & & Nodular & 18.2 & G2 & - \\
\hline & & & & & & & G3 & - \\
\hline \multirow[t]{3}{*}{ Present study } & \multirow[t]{3}{*}{50} & \multirow[t]{3}{*}{$07-56$} & \multirow[t]{3}{*}{02} & \multirow[t]{3}{*}{48} & Diffuse & 82 & G1 & 30 \\
\hline & & & & & Nodular & 18 & G2 & 62 \\
\hline & & & & & & & G3 & 08 \\
\hline
\end{tabular}


Table 3: Distribution of cases according to grades and TSH levels.

\begin{tabular}{|c|c|c|c|c|}
\hline Grade & No.of cases & Normal TSH & Increased TSH & Decreased TSH \\
\hline I & 15 & 14 & 0 & 1 \\
\hline II & 31 & 10 & 20 & 1 \\
\hline III & 04 & 0 & 4 & nil \\
\hline
\end{tabular}

Table 4: Chi square tests and P value for comparison of grades with T3, T4 and TSH.

\begin{tabular}{|l|l|l|l|l|l|}
\hline & Value & df & $\begin{array}{l}\text { P value } \\
\text { (significant if <0.05) }\end{array}$ \\
\hline \multicolumn{5}{|c|}{ N of Valid Cases $\mathbf{5 0}$} \\
\hline Pearson Chi-Square & T3 & 10.232 & 4 & .037 \\
\hline Pearson Chi-Square & T4 & 16.305 & 4 & .003 \\
\hline Pearson Chi-Square & TSH & 22.700 & 4 & $<0.001$ \\
\hline
\end{tabular}

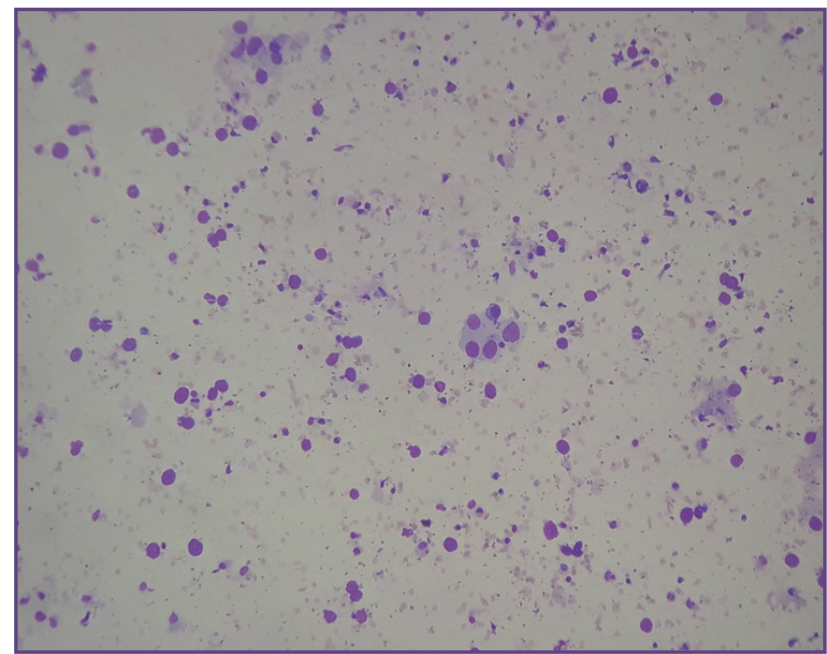

Fig. 1: Grade 1 thyroiditis showing scant lymphocytic infiltrate with few follicular cells (Leishman $x$ 40).

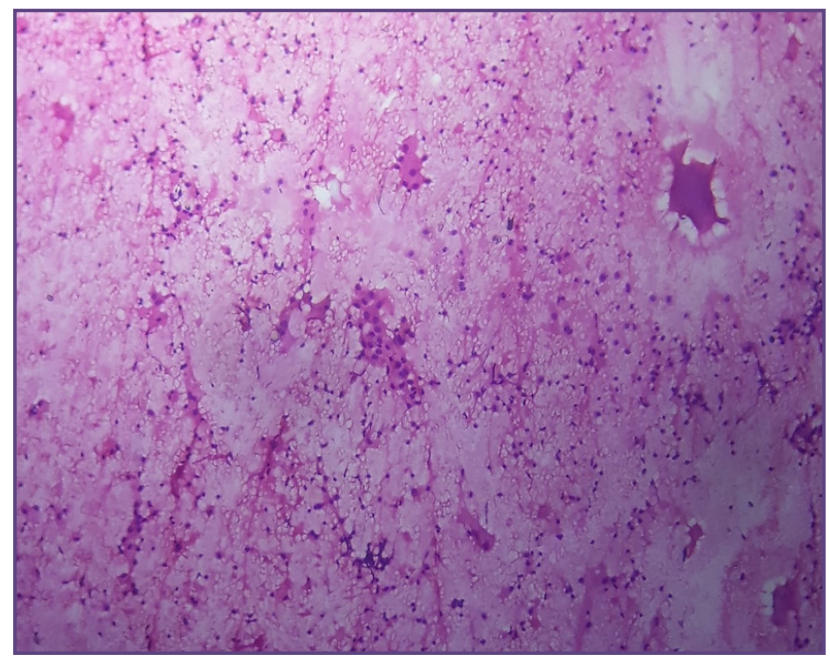

Fig. 3: Grade 2 thyroiditis associated with colloid goitre (H\&E stain x 10).

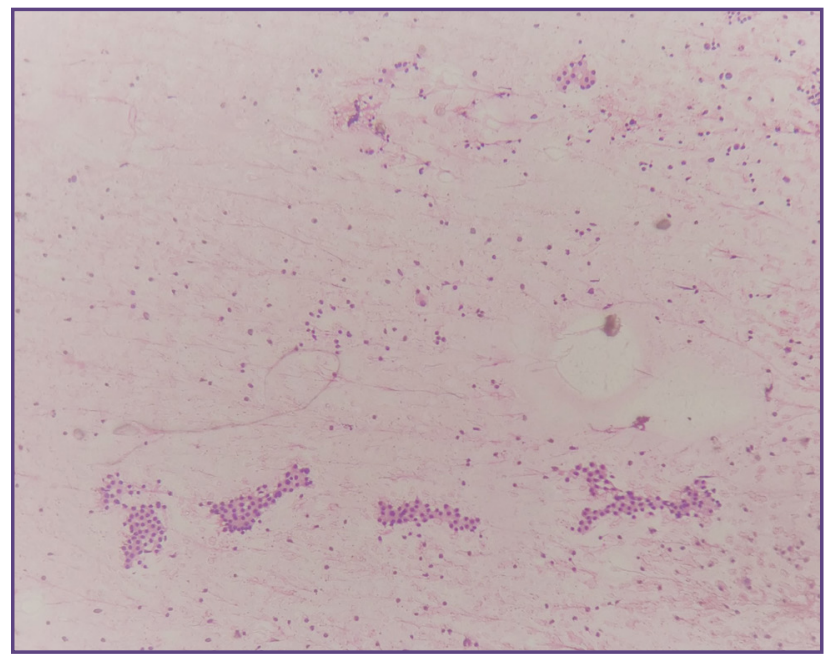

Fig. 2: Grade 1 thyroiditis showing scant lymphocytic infiltrate with few follicular cells (H\&E stain $x$ 10).

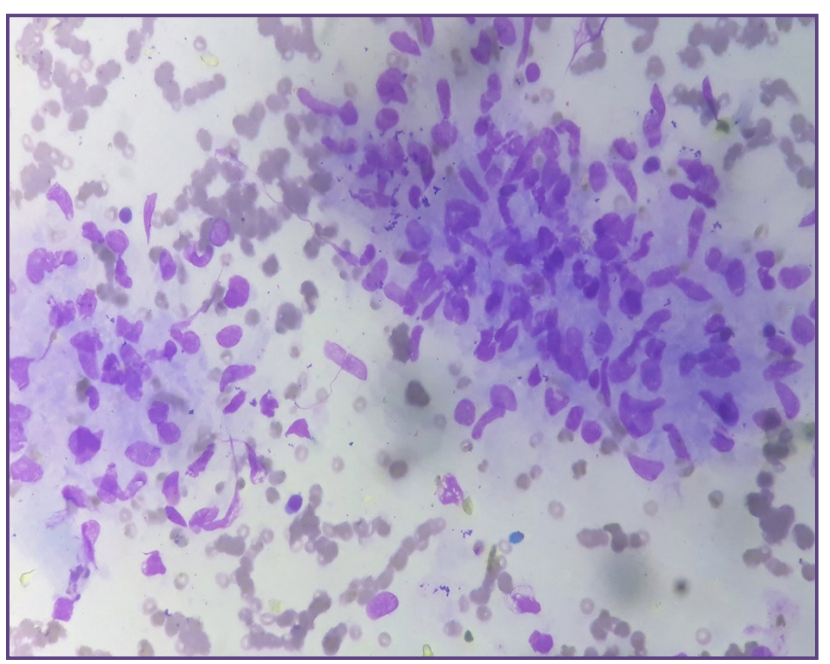

Fig. 4: Granulomas noted in grade 2 thyroiditis (Leishman 40x). 


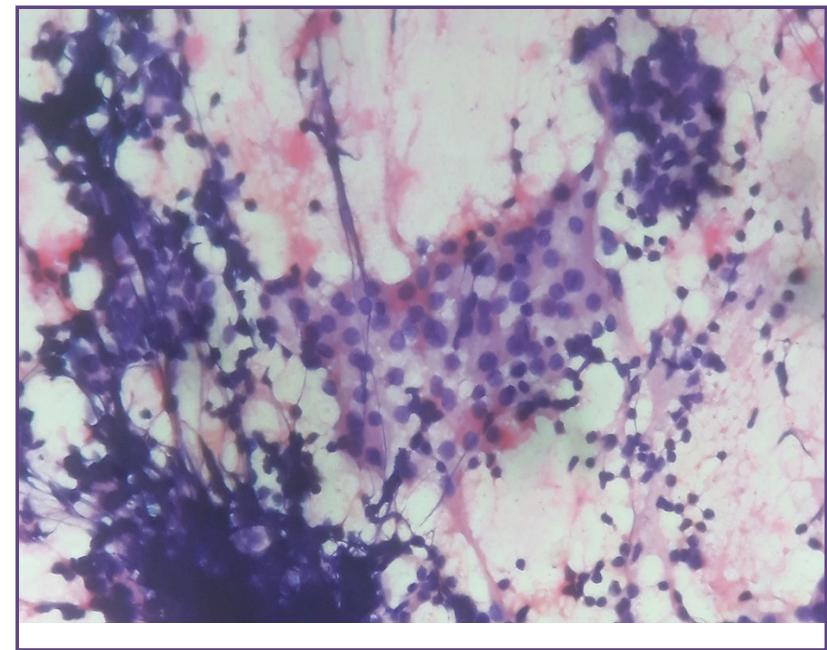

Fig. 5: Grade 3 thyroiditis showing Hurthle cell clusters and lymphocytes in aggregates (Leishman 40x).

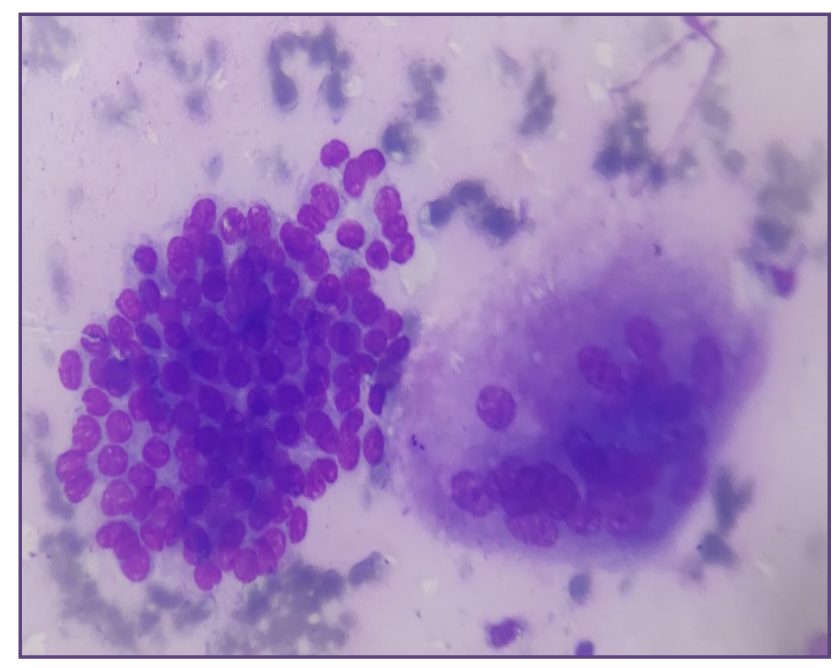

Fig. 7: A case of grade 2 thyroiditis with papillary carcinoma showing granuloma (Leishman 40x),

by Bhatia and Anila et al ${ }^{7,8}$ (Table 2). Thyroid lesions are common in females owing to the effect of female gonadal hormones mainly prolactin, estrogen and X chromosome inactivation on the gland. Also immune system greatly contributes to development of thyroid goitre, nodule and cancer'. Clinically both lobes of the thyroid are usually affected and is diffusely enlarged and firm, but asymmetry with localized nodular enlargement occur ${ }^{10}$. Grossly, the classic form is characterised by diffuse, symmetric, firm and rubbery enlargement of the thyroid ${ }^{11}$. Literature search reveals nodular HT ranging from $2.6 \%$ to $80 \%$. Nodular thyroid was a feature in 09 cases $(18 \%)$ and our study is in concordant with Jayaram et al and Anila et al. Among the nodular thyroid lesions ,53\% exhibited grade 1 cytology and $3.2 \%$ exhibited grade 2 features. Nodules represent the

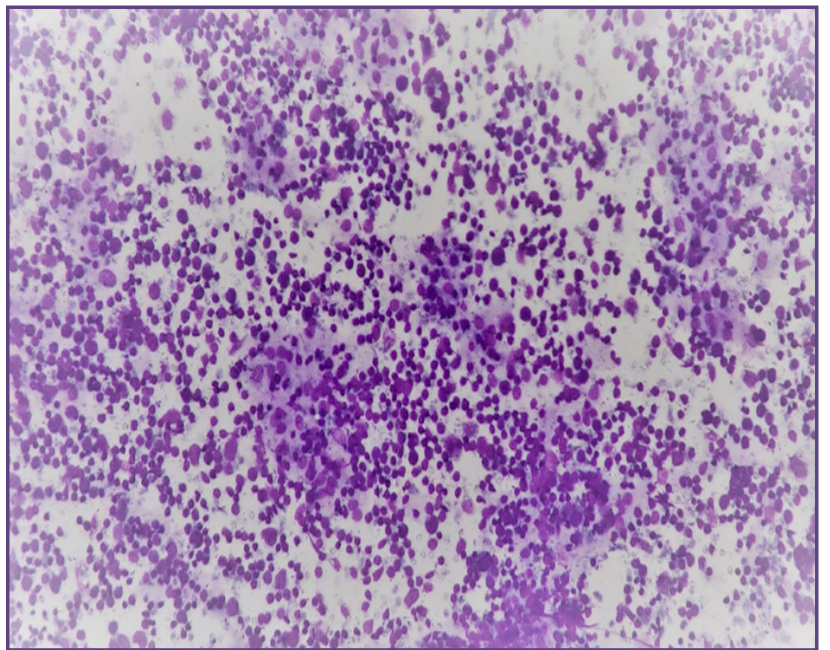

Fig. 6: Grade 3 thyroiditis florid lymphocytic infiltrate with destruction of thyroid follicular cells (Leishman 10x).

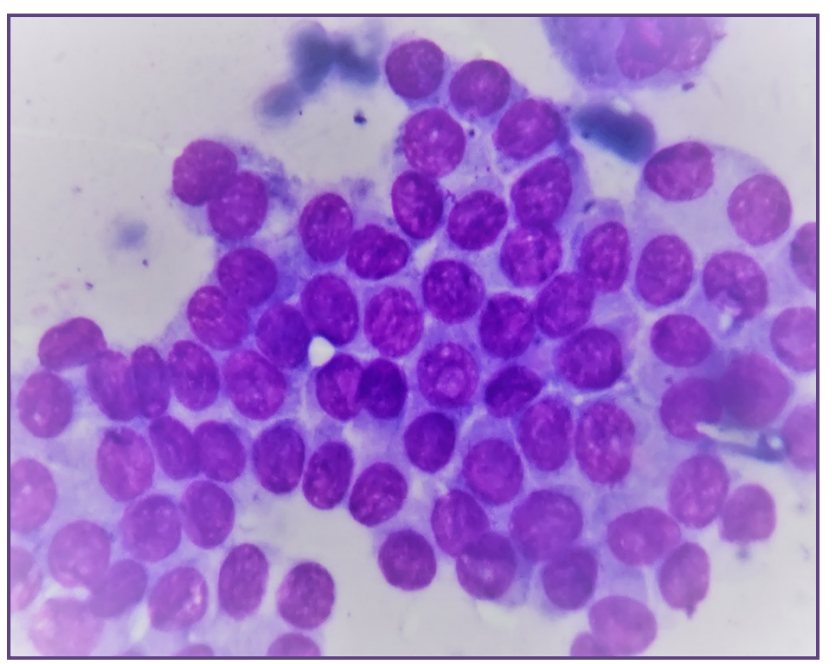

Fig 8: Papillary carcinoma showing intranuclear cytoplasmic inclusion and nuclear grooves (Leishman 40x).

early stage of the disease when clinical and biochemical parameters are not established ${ }^{5}$. Accordingly, in our study nodular thyroid lesions exhibited cytologic features in grade 1 and grade 2 HT only. Also 5 cases of grade 1 patients showed associated feature of colloid goitre on cytology. Majority of the cases in our study had grade 2 thyroiditis comprising of 31 cases $(62 \%)$ similar to studies conducted by Jayaram and Bhatia et al. In Grade $1 \mathrm{HT}$, $93 \%$ were in euthyroid state. Subclinical hypothyroidism with normal T3 and T4 levels and increased TSH levels were seen in $35.4 \%$ of Grade 2 HT (Table 3). 9 out of 50 cases presented with clinical hypothyroidism, showed low T3 and T4 levels with elevated TSH levels. Clinical hypothyroidism was seen only in G2 and G3 thyroiditis. Serological correlation was in concordance with studies 
conducted by Uma et $\mathrm{a}^{12}$ and Ahmed $\mathrm{F}^{13}$. However, majority of the cases show good association between the cytological grades and thyroid profile. $5-10 \%$ of patients with HT progress into papillary carcinoma and less than $1 \%$ may develop malignant lymphoma. High grade B cell lymphomas are reported in HT \& may also be seen as coexisting pathology. Monomorphic population of small or large atypical lymphoid cells is a feature in lymphomas ${ }^{11}$. Hurthle cell neoplasm should be looked for in Hurthle cell rich aspirates. But characteristic feature of monomorphic Hurthle cells, with nucleus exhibiting prominent nucleoli, abundant cytoplasm and absence of lymphocytic infiltrate enables to rule out HT. Cytologically large follicular cells in clusters with nuclear inclusions occur mimicking papillary carcinoma on cytology \& it is also known to occur in HT. However, lack of cytologic findings of papillae, frequent nuclear grooves, nuclear chromatin clearing, thick stringent colloid enables us to rule out the latter. ${ }^{3}$ One case of grade 2 thyroiditis was diagnosed as suspicious for papillary carcinoma on cytological examination in view of papillary clusters with occasional nuclear grooves, seen in addition to polymorphous population of lymphoid cells admixed with Hurthle cells. This patient presented with a nodule in the right lobe of the thyroid. Diagnosis of Hashimotos thyroiditis with suspicion for papillary carcinoma, Bethesda category V was made on cytology. Histopathology confirmed the cytological diagnosis of Papillary carcinoma with associated HT

\section{Conclusion}

FNAC is simple cost effective and quick method for diagnosing HT. Destructive infiltration of thyroid follicles by lymphocytes on cytology remains the gold standard for diagnosing HT in most cases. Also combined evaluation of HT with clinical findings and thyroid profile promotes more accurate diagnosis and early institution of therapy and follow up. FNAC is also necessary to rule out malignant lesions like lymphoma and papillary carcinoma at preliminary cytological level.

\section{Acknowledgements}

Nil

\section{Funding}

Nil

\section{Competing Interests}

No conflict of interest

\section{Reference}

1. Jyoti KR, Eliz T, Kini H. A Study of the Cytomorphological Spectrum of Hashimoto Thyroiditis in Coastal India. International Journal of Advanced Research 2014; 2(4): 1144-47.

2. Gray W, Kocjan G. Diagnostic cytopathology 3rd edition. Churchill livingstone: Elsevier; 2010.

3. Bibbo M,Wilbur D.Comprehensive cytopathology. 4th edition. Philadelphia USA: saunders ; 2008.

4. Anila KR, Nayak N, Jayasree K. Cytomorphologic spectrum of lymphocytic thyroiditis and correlation between cytological grading and biochemical parameters. J Cytol 2016;33:145-9.

5. Bhatia A, Rajwanshi A, Dash RJ, Mittal BR, Saxena AK. Lymphocytic thyroiditis - Is cytological grading significant? A correlation of grades with clinical, biochemical, ultrasonographic and radionuclide parameters. Cytojournal 2007;4:10.

6. Kumar V, Abbas AK, Aster J. Robbins and cotran pathologic basis of disease 9TH Edition. Philadelphia: Elsevier Saunders;2014.

7. Sood N, Nigam JS. Correlation of fine needle aspiration cytology findings with thyroid function test in cases of lymphocytic thyroiditis. J Thyroid Res 2014;430510:1-5.

8. Prasannan M, Kumar SA. Hashimito's thyroiditis - a cytomorphological study with serological correlation. IJSAR 2015; 2(8) :47-52.

9. Li H, Li J. Thyroid disorders in women. Minerva medica 2015; 106(2):109-114.

10. Koss LG. Koss Diagnostic cytology and its histological basis. 5th ed. New York: Lippincott williams and wilkins; 2006.

11. Mohan H. Textbook of pathology. 6th ed. New Delhi: Jaypee brothers; 2010.

12. Cibas ES, Ducatman BS. Diagnostic Principles and Clinical Correlates.3rd Ed. Philadelphia USA: Elsevier; 2009.

13. Uma P. et al. Int J Res Med Sci. 2013 Nov; 1(4):523-31.

14. Faiyaz Ahmad, Ashutosh Kumar, Jyotsana Khatri, Ankita Mittal, Seema Awasthi, Shyamoli Dutta. Cytological Diagnosis of Hashimoto's Thyroiditis Revealing the Increased Frequency than Expected: A Retrospective Study of 750 Thyroid Aspirates. Int J Med Res Prof. 2016; 2(3):143-46.

*Corresponding author:

Dr B R Vani, Professor, Dept of pathology, ESICMC \& PGIMSR, Bangalore

Email: vanidr@yahoo.com

Date of Submission : 31/07/2020

Date of Acceptance : 15/10/2020

Financial or other Competing Interests: None.

Date of Publication : 30/11/2020 